NASA TM-85903

NASA Technical Memorandum 85903

NASA-TM-8590319840021816

\title{
Simulator Evaluation of a Remotely Piloted Vehicle Lateral Landing Task Using a Visual Display
}

\section{Shahan K. Sarrafian}



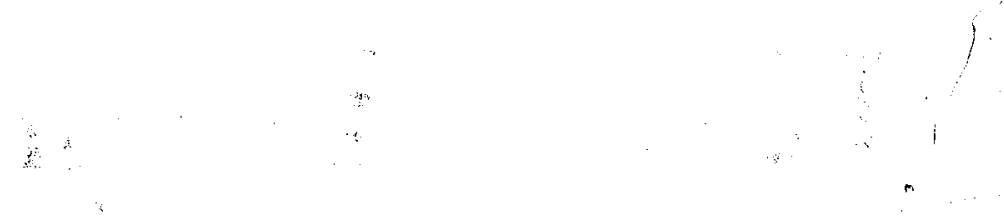
NASA Technical Memorandum 85903

\section{Simulator Evaluation of a Remotely Piloted Vehicle Lateral Landing Task Using a Visual Display}

Shahan K. Sarrafian

Ames Research Center, Dryden Flight Research Facility, Edwards, California 93523

\section{NASก}

National Aeronautics and

Space Administration

Ames Research Center

Dryden Flight Research Facility

Edwards, California 93523 
SIMULATOR EVALUATION OF A REMOTELY PILOTED VEHICLE

LATERAY LANDING TASK USING A VISUAL DISPLAY

Shahan K. Sarrafian*

NASA Ames Research Center

Dryden Flight Research Facility

Edwards, California

\section{Abstract}

A simulator evaluation of a remotely piloted research vehicle was conducted at NASA Ames Research Center's Dryden Flight Research Facility to determine the utility of a visual display when studying the influence of changes in the lateralstick gearing gains during landing approaches. The test vehicle used in this study was a highly maneuverable aircraft technology (HiMAT) aircraft, which is a 0.44-scale version of an envisioned small, single-seat fighter airplane. Handling qualities ratings and comments obtained from pilots using a simulated visual display of a runway scene and a simulated instrument landing system (ILS) display were compared with the results of actual flight tests. The visual display was found to provide an adequate representation of the test vehicle in a visual landing approach, and it improved the roll response cues provided to the pilot. The handing qualities ratings and comments for flight and simulation visual landing approaches correlated well. The ILS simulation results showed reduced correlation compared with the flight results for ILS approaches. Handling qualities criteria for remotely piloted research vehicles are also discussed in this paper.

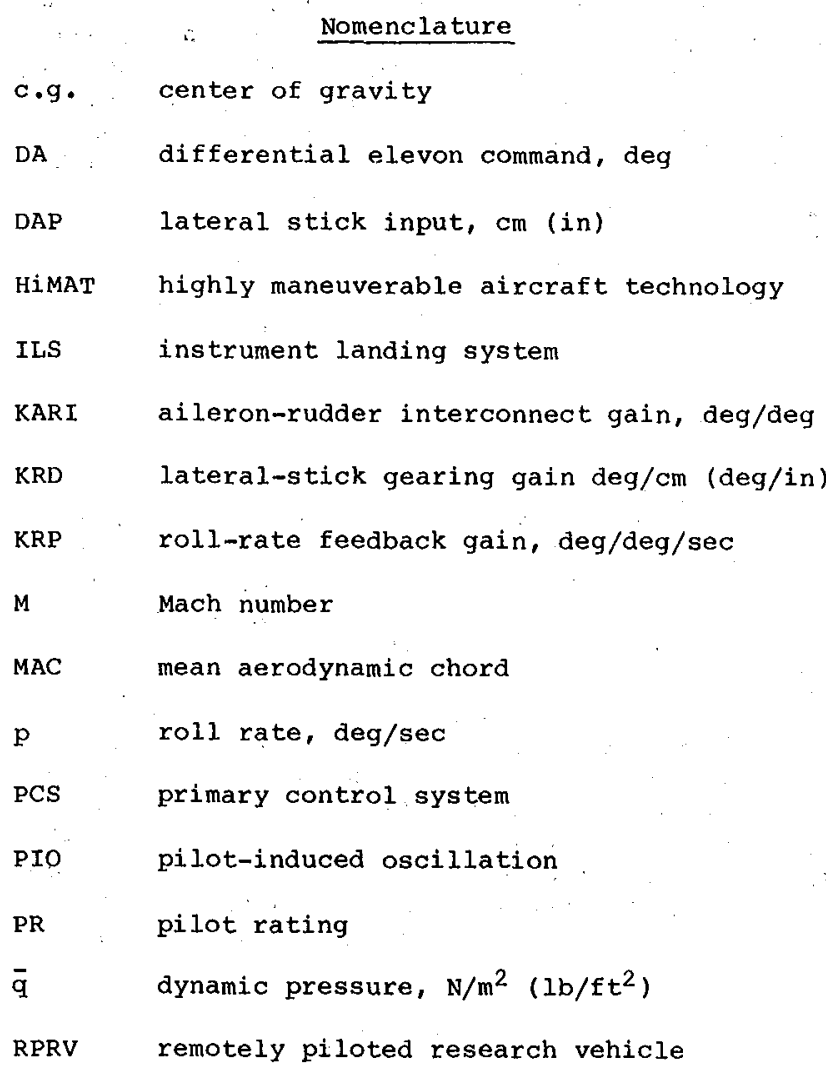

* Aerospace Engineer.

This paper is declared a work of the U.S. Government and therefore is in the public domain. v true velocity, $\mathrm{m} / \mathrm{sec}(\mathrm{ft} / \mathrm{sec})$

VCAS calibrated airspeed, $\mathrm{m} / \mathrm{sec}$ ( $\mathrm{ft} / \mathrm{sec}$ )

\section{Introduction}

The remotely piloted research vehicle (RPRV) is a tool that can be used for exploring unproven and advanced technologies without risking the life of a pilot. The flight testing of RPRVs l allows programs to be conducted at a low cost, in quick response to demand, or when hazardous testing is required to assure the safety of manned vehicles. Yet this type of testing must be performed by the most versatile system available - the pilot. The pilot has the same responsibilities and tasks as if he were onboard the aircraft; this includes guiding the vehicle to a safe landing. The only difference is that he must accomplish this final task from a ground-based cockpit.

The highly maneuverable aircraft technology (HiMAT) aircraft (Fig. 1) is a remotely piloted research vehicle that has completed flight tests to demonstrate advanced fighter technologies at NASA Ames Research Center's Dryden Flight Research Facility. The HiMAT vehicle is a 0.44-scale version of an envisioned small, single-seat fighter airplane. The mission profile of HiMAT (Fig. 2) included a launch from a B-52 aircraft and the acquisition of flight test data. The vehicle was then flown by a NASA test pilot in a fixed groundbased cockpit to a horizontal landing on the Edwards dry lakebed. The vehicle was flown with cockpit display instruments until the landing approach phase of the flight when the camera aboard the aircraft was activated to provide the pilot with a television display during the approach.

During the operational phase of the Himat program, the lateral-stick gearing gain used in the aircraft approach was altered from a variable gain schedule (derived from simulation) to a constant gain schedule. The schedules were changed in response to pilot complaints about oversensitivity in the lateral stick that required high pilot compensation. Before the modified gain schedule was implemented into the primary control system (PCS), it was evaluated in the HiMAT simulator using an instrument landing system (ILS) display; the schedule was found to be satisfactory. postflight comments from HiMAT pilots indicated that the handling qualities during landing approach were significantly improved as a result of the modified gain schedule.

In a separate development, a visual display that was used for engineering purposes was implemented into the simulator during the latter portion of the flight test program when simulation was no longer required to support the remaining flights. While the addition of a visual display is known to significantly improve the fidelity of a simulation system, the need for such a system 
in RPRV simulation at Ames Dryden was felt to be reduced since pilots had an opportunity to conduct proficiency flights with an RPRV Piper Comanche PA-30 aircraft. Nevertheless, when a visual display became available in the simulation laboratory, a decision was made to determine the effectiveness of this type of visual display in the simulation of visual RPRV flight. The RPRV evaluation described in this paper was designed to focus on the utility of a visual display of this type while studying the influence of changes in lateral-stick gearing gains of remotely piloted research vehicle handing qualities during simulated approaches and landings. This study was undertaken to compare evaluations of pilots using a simulated visual display of the runway scene and a simulated IIs display with the results of actual flight tests, using the HiMAT aircraft as a representative remotely piloted research vehicle.

\section{RPRV Visual Landing Approach}

The remotely piloted visual landing approach creates a unique set of problems for the pilot. The television system aboard the vehicle does not provide all the visual cues found in the real world. In particular, the peripheral field of view is not available to the RPRV pilot. A pilot first detects large attitude excursions from his peripheral field of view. These attitude excursions are not immediately interpreted in roll as they are in pitch for a two-dimensional RPRV visual display. 2 Lack of motion feedback to the RPRV pilot prevents him from experiencing the acceleration cues necessary to satisfactorily control the aircraft in turbulence. This increases the possibility of exceeding boundary limitations in the flight envelope. These factors were present during the HiMAT visual landing approach. Because of this, a wellbehaved vehicle is required for RPRV flight. The lack of the visual and motion cues, particularly in adverse situations, forced the pilots to fly the HiMAT vehicle in an open-loop fashion.

\section{Hi MAT Landing Approach Procedure}

Standard procedures for the HiMAT vehicle flight approach included a visual transition by the pilot from the IIS glideslope indicators to the television monitor when the vehicle was 5.6 to $9.3 \mathrm{~km}$ ( 3 to $5 \mathrm{n}$. mi.) from touchdown. This depended primarily on the sun angle and the viewing range of the camera. Once the television display was activated, it became the primary source of information for the pilot. The desired touchdown conditions are presented in Table 1. The conditions are broadly defined, as the pilot was asked to make a long, straight-in approach on the glideslope to the lakebed. Following the flight, the pilot was asked to give handling qualities ratings and comments for both the ILS and the visual portions of the actual landing approach task.

\section{HiMAT Television Camera and Display}

The forward-looking television camera aboard the aircraft was rigidly mounted in the canopy (Fig. 3). The camera was mounted over the fuselage centerline with a $7^{\circ}$ depression angle. The camera field of view was approximately $14^{\circ}$ in the horizontal plane and $10^{\circ}$ in the vertical plane (Fig. 4): It included the noseboom configuration, which the pilots considered useful as an attitude indicator.
The television monitor had a 525-line vertical scan, which is approximately the quality of a standard video monitor.

\section{Simulation Facility}

The simulation laboratory at Ames Dryden was used for the evaluation. The HiMAT simulation system ${ }^{3}$ was essential to the flight qualification of the HiMAT vehicle. The visual display system was integrated into the simulation system after the developmental stages of the HiMAT program were completed.

\section{Simulation Cockpit}

The evaluation was conducted in the HiMAT fixed-base simulator shown in Fig. 5. The instrument panel layout was identical to that used during flight. The ILS and glideslope indicators were used to ensure task consistency. The feel system of the control stick that was used in flight was implemented into the simulator.

\section{Simulation software}

The all-digital version of the HiMAT simulation $^{3}$ was used for the evaluation. This version is implemented completely through software; that is, all flight control system hardware elements were modeled. This version was the principal tool for the final design and development of the primary control system (PCS). The all-digital version was also used for initial pilot evaluations in the flight program.

The portion of the PCS relating to roll control is presented in Fig. 6. The lateral-stick gearing gain (KRD) modifies the lateral stick input (DAP) before routing to both the differential elevon command (DA) and through the aileron-rudder interconnect gain (KARI) to the rudder command. Roll-rate feedback is passed through the roll-rate feedback gain (KRP) to DA. The location of the aircraft's center of gravity (c.g.) was maintained at 5 percent of the mean aerodynamic chord (MAC). This c.g. location resulted in a bare airframe that had an unstable 2- to 3-percent longitudinal static margin.

Visual Display

The simulator was operated with an Evans and sutherland picture system ${ }^{4}$ by using a calligraphic monitor. The monitor provided a $28^{\circ}$ field of view in the horizontal plane and a $21^{\circ}$ field of view in the vertical plane. This field of view was larger than that used in the actual flights; however, the peripheral field of view was still nonexistent. The monitor had a 4094-line scan in the vertical plane. This produced a level of resolution significantly highex than that on the television monitor that was used in flight. The refresh rate was maintained at 60 frames per sec. The $7^{\circ}$ depression angle of the camera aboard the aircraft was implemented into the visual display simulation. The noseboom configuration of the test vehicle was included in the visual display.

\section{Test protocol}

The study was structured to evaluate the lateral-stick gearing gain in simulated RPRV approaches and landings. A lateral landing 
approach task was used throughout the evaluation to exercise the effect of the lateralstick gearing gain on the aircraft's lateraldirectional characteristics. The test matrix was designed to detect those lateral-stick gearing gains which may or may not be suitable for an RPRV landing approach.

\section{Iateral-Stick Gearing Gain Test Schedules}

The lateral-stick gearing gain schedules used in the evaluation consisted of the modified gain used in flight ( $K R D=1.6 \mathrm{deg} / \mathrm{cm}(4 \mathrm{deg} / \mathrm{in})$ ) and four additional constant gains (KRD $=3.1(8)$, $4.7(12), 6.3(16), 7.9(20) \mathrm{deg} / \mathrm{cm}(\mathrm{deg} / \mathrm{in}))$, shown in Fig. 7. The original gain schedule used in flight (for S.I. units, KRD $=33,931 / \bar{q}$; for U.S. units, $K R D=1800 / \bar{q})$ was used solely as a point of interest and had a variable range ( $K R D=3.1$ to $7.1 \mathrm{deg} / \mathrm{cm}(8$ to $18 \mathrm{deg} / \mathrm{in}))$. The original gain schedule was not used in the validation portion of the evaluation because it had been replaced with the modified gain in the actual flight test program. The six gain schedules were presented to the pilot in a blind sequence. This allowed the gains to be evaluated in an objective fashion.

\section{Initial Conditions}

The initial conditions of the simulated landing approach are presented in Table 2. The HiMAT aircraft was positioned with a lateral deviation of about $6^{\circ}$ to the left of the horizontal glideslope (Fig. 8). An alternative set of conditions, shown in Fig. 9, positioned the aircraft on the glideslope with no lateral deviation, but at a lower altitude $(1372 \mathrm{~m}(4500 \mathrm{ft}))$. This set of initial conditions allowed a greater number of approaches to be flown within a limited period of time (when time was at a premium). This alternative set of initial conditions did not prevent the pilots from adequately evaluating the roll response characteristics of the aircraft.

The landing approaches were first conducted under ILS conditions and then repeated using the visual display. Each set of conditions was flown in both calm and turbulent air. The calm conditions were representative of actual approaches flown by the HiMAT pilots. The Dryden form of the turbulence spectra provided disturbances of $0.91 \mathrm{~m} / \mathrm{sec}$ ( $3 \mathrm{ft} / \mathrm{sec}$ ) rms in each axis simultaneously. This turbulence created adverse conditions under which a gain schedule could be evaluated. The gusts were washed out $46 \mathrm{~m}$ (150 ft) above the runway surface.

\section{Evaluation Pilots}

Three NASA test pilots were selected for the evaluation: Pilot 1 had HiMAT flight experience with the modified gain schedule; pilot 2 had HiMAT flight experience with both the original and modified gain schedules; and pilot 3 had no previous HiMAT flight experience, but had extensive handling qualities evaluation experience.

\section{Test Procedure}

The pilots were asked to fly the approach to touchdown with a particular lateral-stick gearing gain. Desired touchdown conditions were identical to those used in actual landing approaches. Practice approaches were flown by each pilot to eliminate any learning curve effects. The pilots were encouraged to fly more than one approach if they felt it necessary to properly evaluate a configuration. Following each approach, the pilots evaluated the lateral-directional handing qualities by using a Cooper-Harper rating scale (Fig. 10). Each pilot was also asked to comment on the roll response and maneuverability of the vehicle. Any overcontrol or lateral pilot-induced oscillation (PIO) tendencies were also noted. Both the flight and simulation approaches were made wi thout rudder inputs.

\section{Results}

The constant gain schedules were flown by each pilot under ILS and visual conditions in both calm and turbulent air. The handling qualities results display distinct trends for increasing lateralstick gearing gains. These results are presented in terms of Cooper-Harper pilot ratings, and performance level ratings in accordance with militaryspecification (MIL-SPEC) MIL-F-8785C. 5 A tabulation of the pilot ratings and comments for each approach in the evaluation is located in Ref. 6 .

\section{ILS Approaches}

The simulation results for the ILS approaches in calm and turbulent air are presented in Figs. $11(a)$ and $11(b)$. The trend appears to be consistent for both types of atmospheric conditions. The modified gain schedule (KRD = $1.6 \mathrm{deg} / \mathrm{cm}(4 \mathrm{deg} / \mathrm{in})$ ) was found to be sluggish, although desired performance could be achieved most of the time. A KRD value of $4.7 \mathrm{deg} / \mathrm{cm}$ (12 deg/in) produced a level I performance for the pilots in most cases. The turbulent conditions did not significantly degrade the pilots' evaluation of the vehicle's handling qualities.

\section{Visual Display Approaches}

The simulation results for the visual display approaches in calm and turbulent air are presented in Figs. 11(c) and 11(d). The lower gains in calm air (Fig. 11(c)) were preferred over the ILS approaches flown under identical conditions (Fig. 11(a)). Conversely, higher gains were preferred with the ILS approaches (Fig. 11(a)) than with visual display approaches (Fig. 11(c)). This behavior was attributed to the apparent increase in response when visual display approaches were flown. This increase in response led to improved roll. control power with the lower gains and overcontrol tendencies with the higher gains. A KRD gain of $3.1 \mathrm{deg} / \mathrm{cm}$ ( $8 \mathrm{deg} / \mathrm{in}$ ) yielded consistent level I performance under calm conditions.

The visual display approaches flown in turbulent air (Fig. 11(d)) resulted in degraded performance compared to the calm conditions (Fig. 11(c)). The gusts were enhanced by the visual display and were considered by the pilots to be a factor in the control power of the vehicle. This resulted in solid level. II performance and a slight preference for lower gains, although the trend is less clear.

Comparison with Flight Results

The handing qualities ratings and comments for actual HiMAT landing approaches are presented in Table 3. The ratings reflect the improvement in 
lateral-directional response provided by the modified gain schedule $(K R D=1.6 \mathrm{deg} / \mathrm{cm}(4 \mathrm{deg} / \mathrm{in}))$. These flight ratings, obtained from the ILS and visual portions of the landing approaches, were averaged and compared with corresponding averaged simulation ratings from the calm-air ILS and visual display approaches which best represented actual flight conditions. These results (for the two pilots with HiMAT flight experience) are shown in Fig. 12. The visual display ratings compare well with the visual flight ratings, indicating the potential of the visual display simulation for obtaining results comparable to those found in flight. The ILS results in Fig. 12 show reduced correlation relative to the visual results. The ILS handing qualities ratings (Figs. 11 (a) and $11(b))$ indicate that a higher gain is required to satisfactorily correlate with the ILS flight results.

Pilot comments made following the visual HiMAT vehicle flight approaches were consistent with those found in the visual simulation. pilot 2 said the constant gain ( $K R D=1.6 \mathrm{deg} / \mathrm{cm}(4 \mathrm{deg} / \mathrm{in})$ ) was insensitive in roll during flight but provided good lateral control; this was consistent with his comments on the visual simulation. Pilot 1 said the aircraft was sluggish in roll in the ILS simulation but acceptable in visual flight. With the use of the visual display simulation, pilot 1 noted improved roll response, although some sluggishness was still present. He felt the visual display provided significantly improved cues for the HiMAT approach, as did pilot 2. Pilot 3 stated that the visual display increased the apparent sensitivity of the gains and amplified large bank-angle excursions when compared with the ILS approaches.

The lateral control activity under ILS and visual conditions for the simulation and flight approaches compared satisfactorily, as indicated in Fig. 13. Conflicting scheduling of simulation prevented the acquisition of data from the same pilot (Fig. 13). Therefore, a comparison of the relative control activity areas is only qualitative.

\section{MIL-SPEC Compliance}

The HiMAT simulation roll characteristics were documented at the conclusion of the evaluation. The fidelity of the simulation was considered very good with respect to the aircraft's flight performance. The steady-state roll rate for a maximum lateral step input using the modified gain schedule was $48 \mathrm{deg} / \mathrm{sec}$ at 250 knots. A roll-mode time constant of $0.4 \mathrm{sec}$ was measured from the data, which is considered to be level I for class IV, category $C$ aircraft in MIL-SPEC MIL-F-8785C.6 It must be emphasized that MIL-F-8785C is a manned-aircraft criterion.

The simulation roll performance results for the five constant gain schedules used in the evaluation are presented in Fig. 14. The MIL-F-8785C handling qualities boundaries (levels I, II, and III) are also shown; however, these boundaries are highly suspect. 7 There are indications that these boundaries should be reduced by half for military-type remotely piloted vehicles. However, according to the pilot ratings and comments recorded in this evaluation, these boundaries should be relaxed for' remotely piloted research vehicles. Under ideal conditions, a research mission is considered to be less demanding than a combat or military mission. A comparison of the time-to-bank results for the constant gain schedules in Fig. 14 shows roll performance of level I for the higher gains. The roll performance for these gains was rated level II in the evaluation. The original gain schedule is also illustrated in Fig. 14; it displays level I roll performance characteristics based on MIL-F-8785C, but received level II ratings in the evaluation.

The HiMAT simulation maximum roll control force was found to be level II for class IV, category $C$ aircraft in MIL-F-8785C. The allowable breakout force for the lateral stick was level I to II. Again, these comparisons have been made to mannedairciaft criteria. The HiMAT lateral control stick characteristics are presented in Table 4 . No specific pilot comments regarding the stick breakout or force gradient were noted.

\section{Discussion}

The pilots were able to complete the required task under both nominal and adverse conditions. Determining an optimal range for constant lateralstick gearing gains became a choice between the pilots' ability to perform smali precision corrections and to perform gross maneuvers. The pilots generally found the lower gains satisfactory for precision corrections throughout the task, although the aircraft appeared sluggish or insensitive..in. roll. This insensitivity became unacceptable in the presence of excessive turbulence or in a situation during an actual approach that would require rapid maneuvering. Extreme conditions of this nature were rarely encountered during the landing approach phase of the flight. The pilots expressed no concern about the controllability of the vehicle with the lower gains. The higher gains provided the maneuverability, but were oscillatory and had a tendency to result in overcontrol or in lateral. PIO. The pilots experienced lateral PIO, tendencies with the higher gains on the visual display approaches in calm and turbulent air (Figs. 11(c) and $11(d))$. The optimal range of constant lateralstick gearing gain schedules had to provide adequate maneuverability and allow for precision corrections during the simulated HiMAT aircraft visual. approach. Considering that the actual HiMAT vehicle landing approaches were flown in well-behaved atmospheric conditions, a slightly higher lateralstick gearing gain than the modified gain schedule used in flight. would provide solid lateral control to the RPRV pilot and allow for some increased maneuvering capability. values of KRD between 2.4 and $3.1 \mathrm{deg} / \mathrm{cm}$ ( 6 and $8 \mathrm{deg} / \mathrm{in}$ ) provided such requirements.

The original gain schedule was flown under the simulated flight conditions in the evaluation, and it was found to induce lateral stick sensitivity problems and overcontrol tendencies. It was not included in the evaluation results. Based on actual flight experience, the original gain schedule was undesirable because of its oversensitivity in roll; the higher constant gains evaluated in the study that represented the higher range of the original gain schedule confirmed this result.

\section{Concluding Remarks}

A simulator evaluation of a remotely piloted research vehicle (RPRV) was conducted to determine the utility of a visual display when studying the 
influence of changes in lateral-stick gearing gains during landing approaches. Handling qualities ratings and comments obtained from the pilots using a simulated visual display of a runway scene and a simulated instrument landing system (ILS) display were compared with the results of actual flight tests. The roll characteristics of the RPRV were also compared to handling qualities criteria in MIL-F-8785C. The highly maneuverable aircraft technology (HiMAT) aircraft was the remotely piloted research vehicle studied in this evaluation. This vehicle is a $0.44-s c a l e$ version of an envisioned small, single-seat fighter airplane.

The visual display simulation of the RPRV provided an adequate representation of the visual flight landing approach, which improved the validity of the simulator. Improved cues regarding roll response resulted from the use of the visual display. The presence of these cues was essential to the lateral control of the vehicle during landing approaches. The use of a visual display can increase the simulator's effectiveness as a design tool in RPRV flight programs.

The handing qualities results obtained from the visual landing approach simulation compared well with the visual flight results. Handling qualities ratings and comments for a given lateralstick gearing gain were consistent with those found from actual flight landing approaches. A range of lateral-stick gearing gains was found that provided adequate maneuverability and allowed for precision movements during a simulated visual landing approach. This range of gains was slightly higher than the modified gain that was flown in flight landing approaches.

The ILS simulation results suggested that the modified lateral-stick gearing gain schedule used in flight does not provide desired performance during a flight landing approach. This did not correlate well with the flight results. The ILS simulation results indicated that a lateral-stick gearing gain higher than the optimal range found with the visual simulation produced desired performance under all evaluation conditions.
The roll handling qualities characteristics of the simulated test vehicle were determined during the evaluation. The roll-mode time constant was calculated to be level $I$ and the maximum roll control force was measured and determined to be level I to II according to MIL-F-8785C. The roll performance of the optimal range of lateral-stick gearing gains determined from this evaluation improved the handling qualities ratings by approximately one level over the modified gain that was used in flight. It should be emphasized that manned-aircraft handling qualities criteria for military missions were applied to the results. The roll performance results from this study indicate that the MIL-F-8785C roll performance handling qualities boundaries could be relaxed for remotely piloted research vehicles.

\section{References}

$1_{\text {Reed, R. Dale, "RPRVs: The First and Future }}$ Flights," Astronautics \& Aeronautics, vol. 12, no. 4, Apr. 1974, pp. 26-42.

${ }^{2}$ Reed, Lawrence E., "Visual-Proprioceptive Cue Conflicts in the Control of Remotely piloted vehicles," Air Force Human Resources Laboratory, AFHRL-TR-77-57, 1977.

${ }^{3}$ Evans, Martha $B_{.}$, and Schilling, Lawrence J., "The Role of Simulation in the Development and Flight Test of the HiMAT vehicle," NASA TM-84912, 1984.

${ }^{4}$ Mantle, M., and Mortenson, D., "picture System 2/PDP-11 Reference Manual," Second ed., Evans and Sutherland Corp., E and S 901130-001 A1, 22 Nov. 1977.

5 "Military Specification Flying Qualities of Pi loted Airplanes," MIL-F-8785C, Nov. 1980.

${ }^{6}$ Sarrafian, Shahan $K_{.}$, "Evaluation of HiMAT Aircraft Landing Approach Lateral Control Gearing Using Simulation and a Visual Display," NASA TM-84916, 1984 .

${ }^{7}$ Prosser, Charles F., and wiler, Curtiss D. "RPV Flying Qualities Design Criteria," Air Force Flight Dynamics Laboratory, AFFDL-TR-76-125, 1976.

Table 1 HiMAT aircraft desired touchdown conditions

Longitudinal touchdown dispersion, $\mathrm{km}$ (n. mi.)..... $\pm 1.9( \pm 1)$ Lateral touchdown dispersion, $m(f t) . . . . . . . \pm 46( \pm 150)$ Touchdown speed (indicated), knots ........ 180 to 190 Touchdown altitude rate, $\mathrm{m} / \mathrm{s}(\mathrm{ft} / \mathrm{s})$...... o to $1.5(0$ to 5$)$

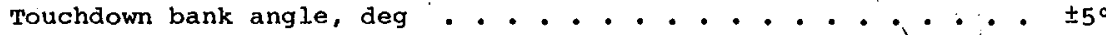


Table 2 simulated landing approach initial conditions

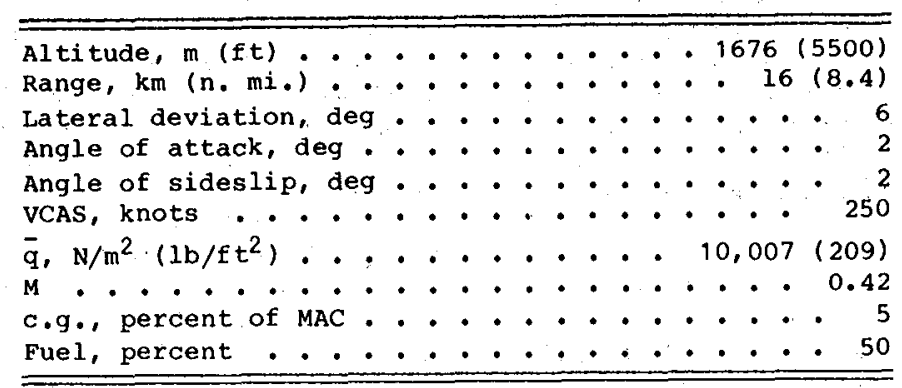

Table 3 HiMAT aircraft landing approach flight ratings and comments

( 5 percent of MAC c.g. configuration; responses refer to lateral-directional handling qualities)

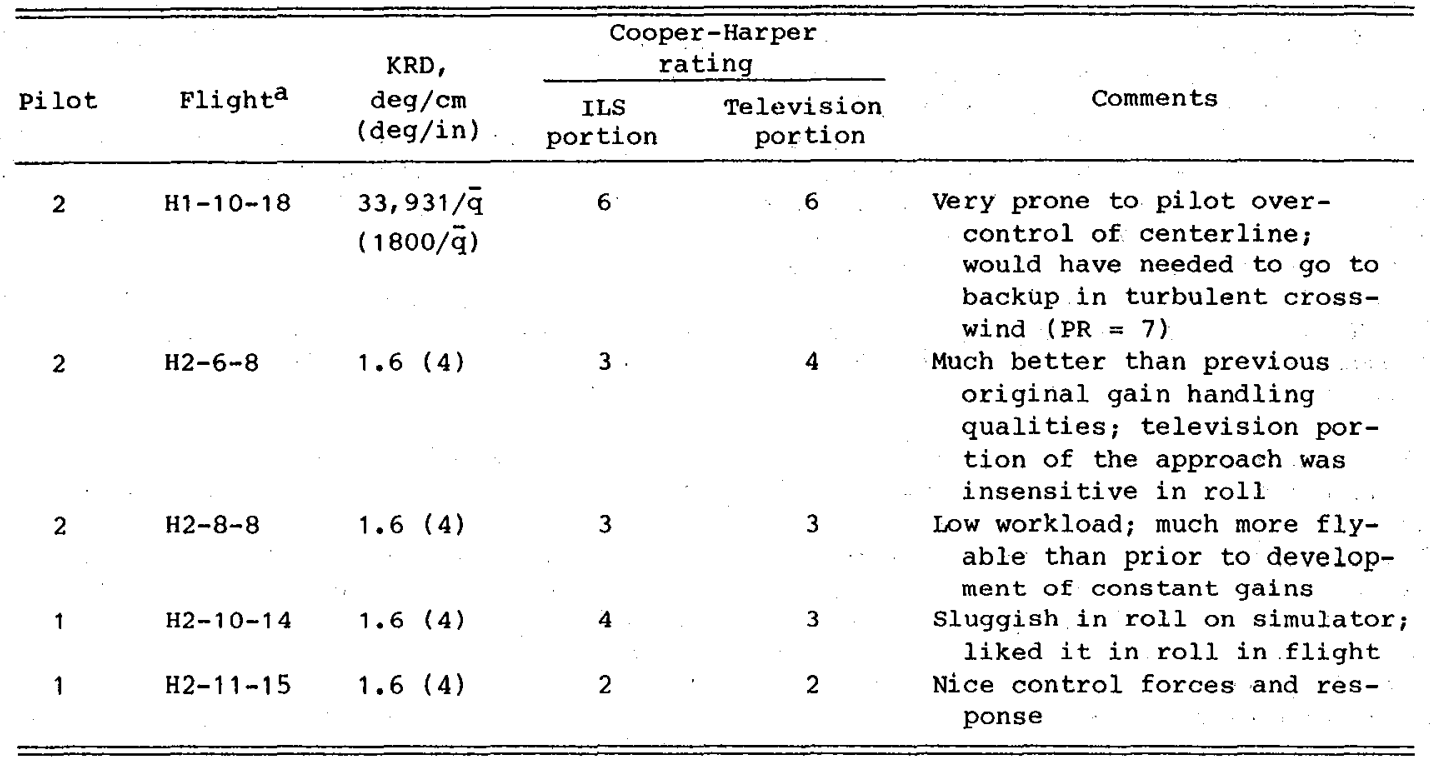

a Entries refer to vehicle number, launch number, and number of times the vehicle was aloft.

Table 4 HiMAT lateral control stick characteristics (Maximum lateral $\mathrm{stick}= \pm 10.8 \mathrm{~cm}( \pm 4.25 \mathrm{in})$ )

\begin{tabular}{lc}
\hline Stick characteristics & Handling qualities level \\
\hline $\begin{array}{l}\text { Force gradient }=8.8 \mathrm{~N} / \mathrm{cm}\left(5.0 \mathrm{lb} / \mathrm{in}^{2}\right. \\
\text { Maximum roll control force }=\end{array}$ & Not applicable \\
$95.0 \mathrm{~N}(21.3 \mathrm{lb})$ & I \\
Breakout force $=11.6 \mathrm{~N}(1.6 \mathrm{lb})$ & to II \\
\hline
\end{tabular}




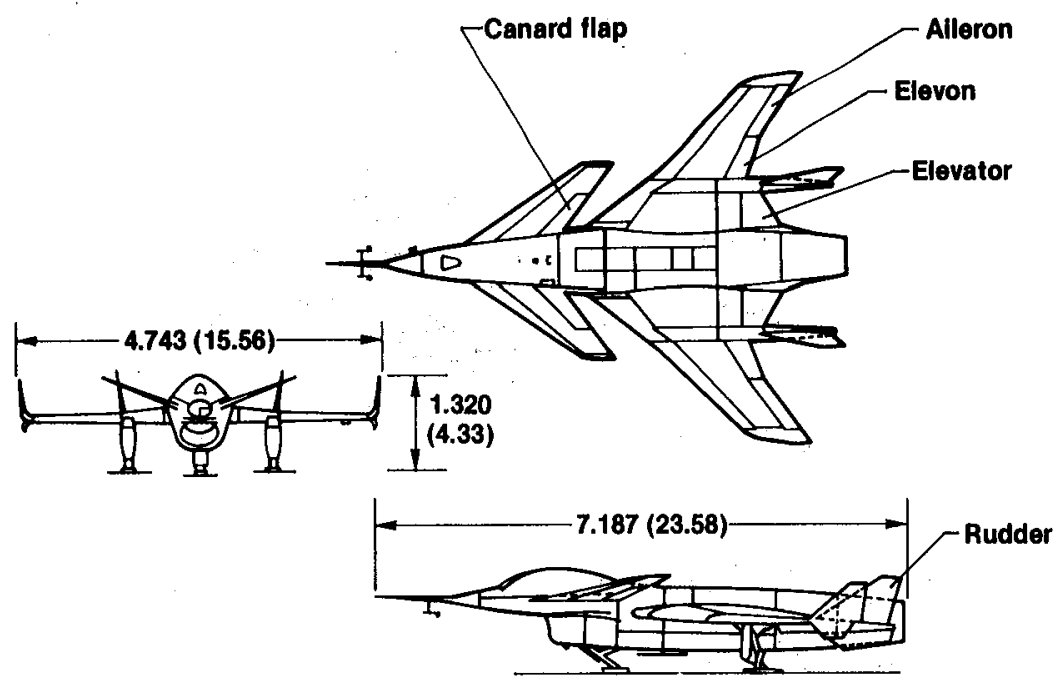

Fig. I Three-view of HiMaT vehicle. Dimensions are in $m(f t)$.

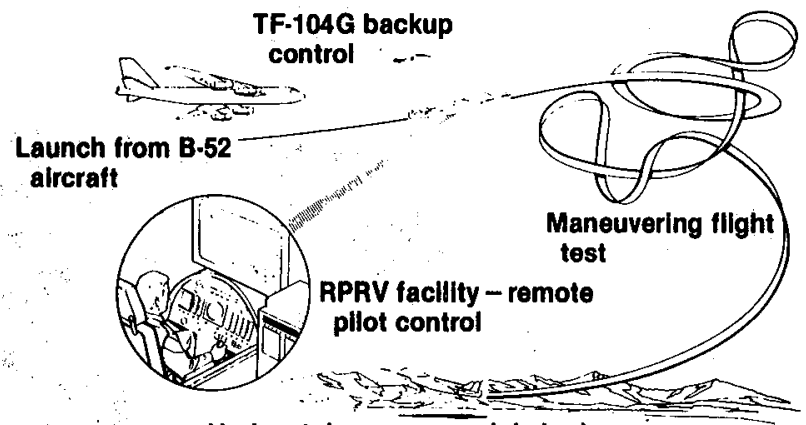

Horizontal recovery on lakebed

at Edwards AFB

Fig. 2 HiMAT mission profile.

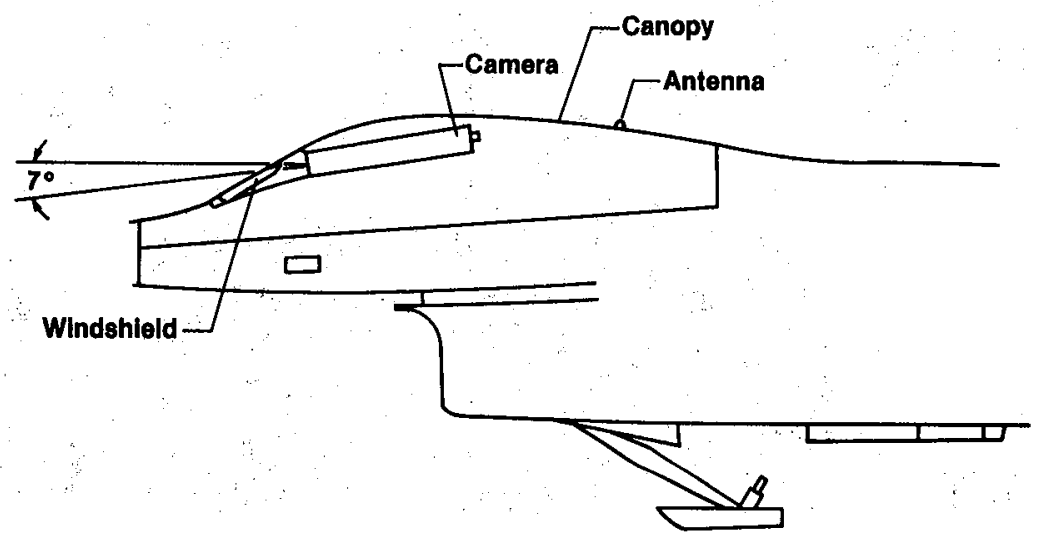

Fig. 3 HiMaT vehicle camera location. 


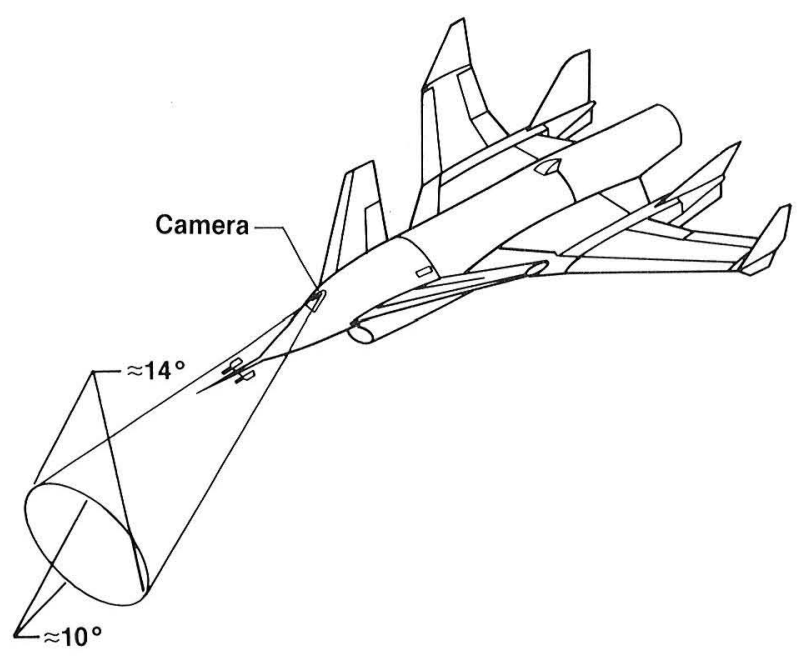

Fig. 4 Himat vehicle camera field

of view; $14^{\circ}$ in the horizontal

plane and $10^{\circ}$ in the vertical plane.

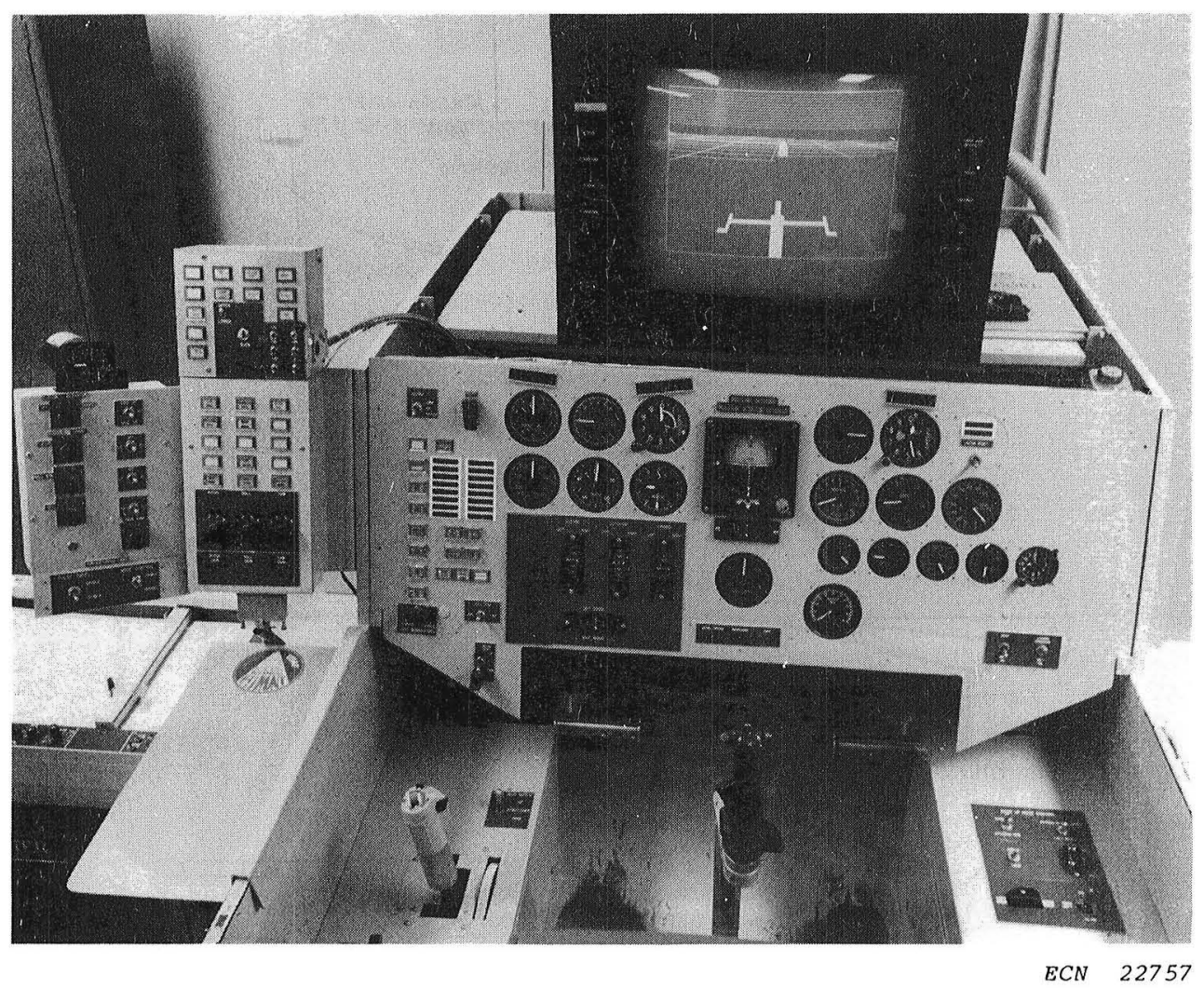

Fig. 5 HiMAT simulation cockpit. 


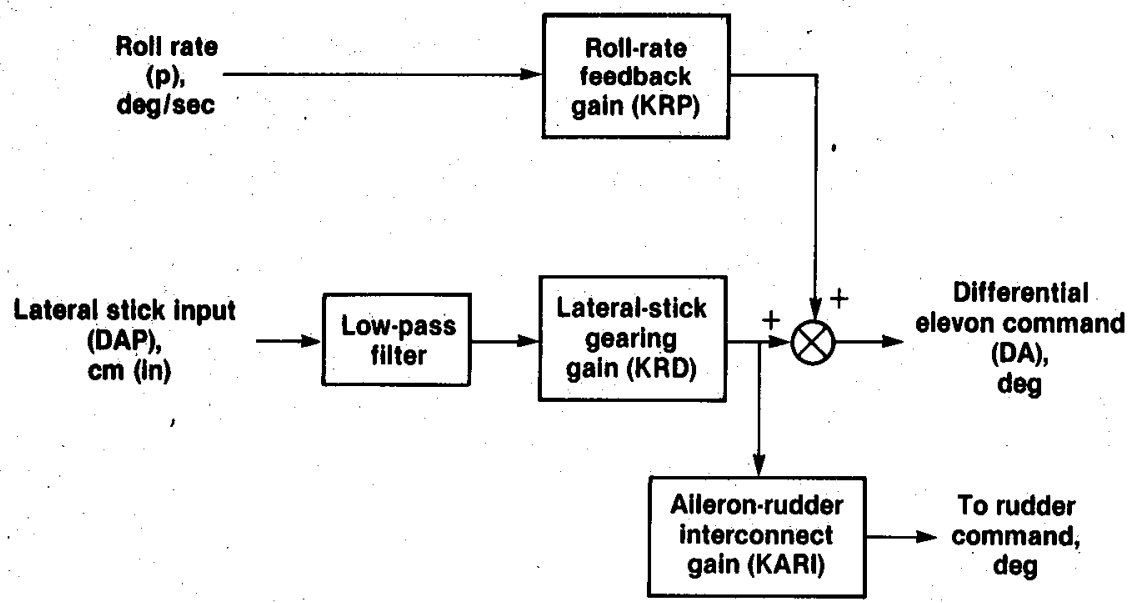

Fig. 6 HiMaT vehicle primary roll control system.

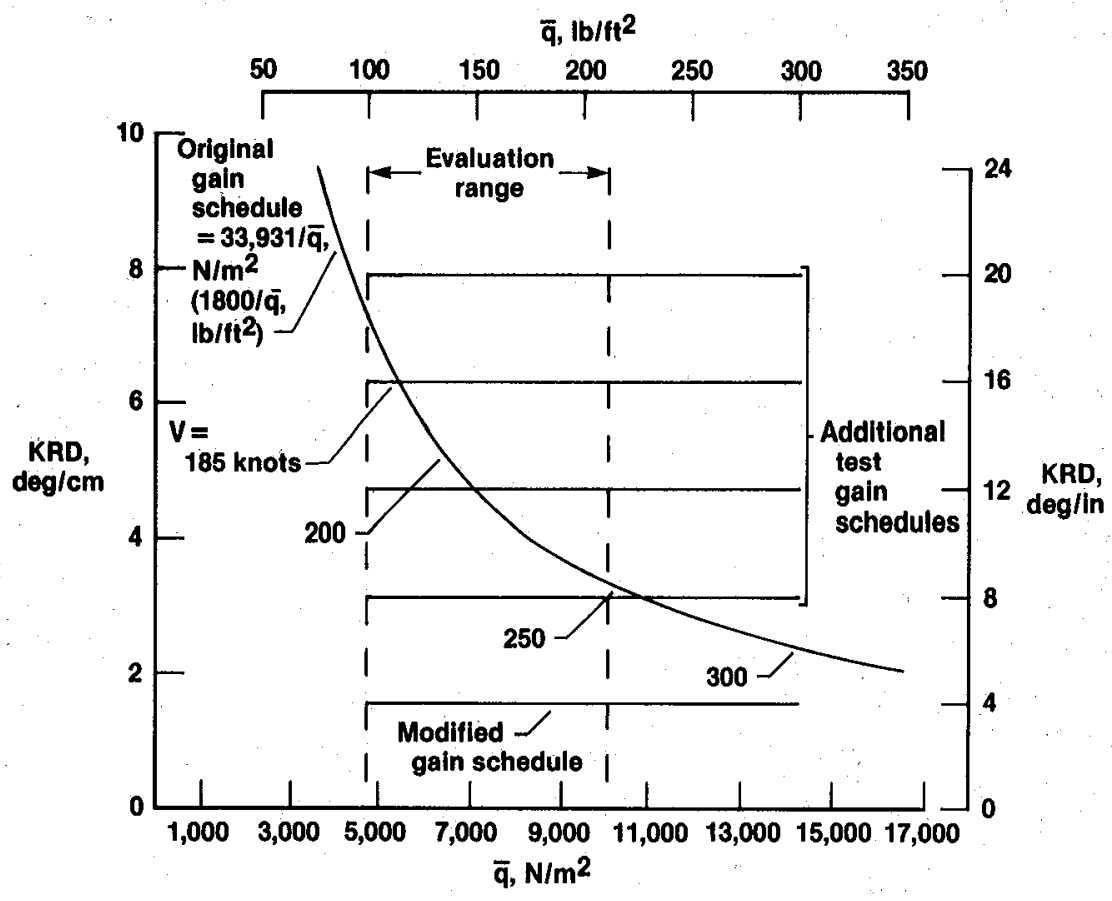

Fig. 7 HiMAT lateral-stick gearing gain schedules. Mach number $\langle 1.0 ; c .9 .=5$ percent of MAC; and maximum lateral stick $= \pm 10.8 \mathrm{~cm}( \pm 4.25 \mathrm{in})$. 


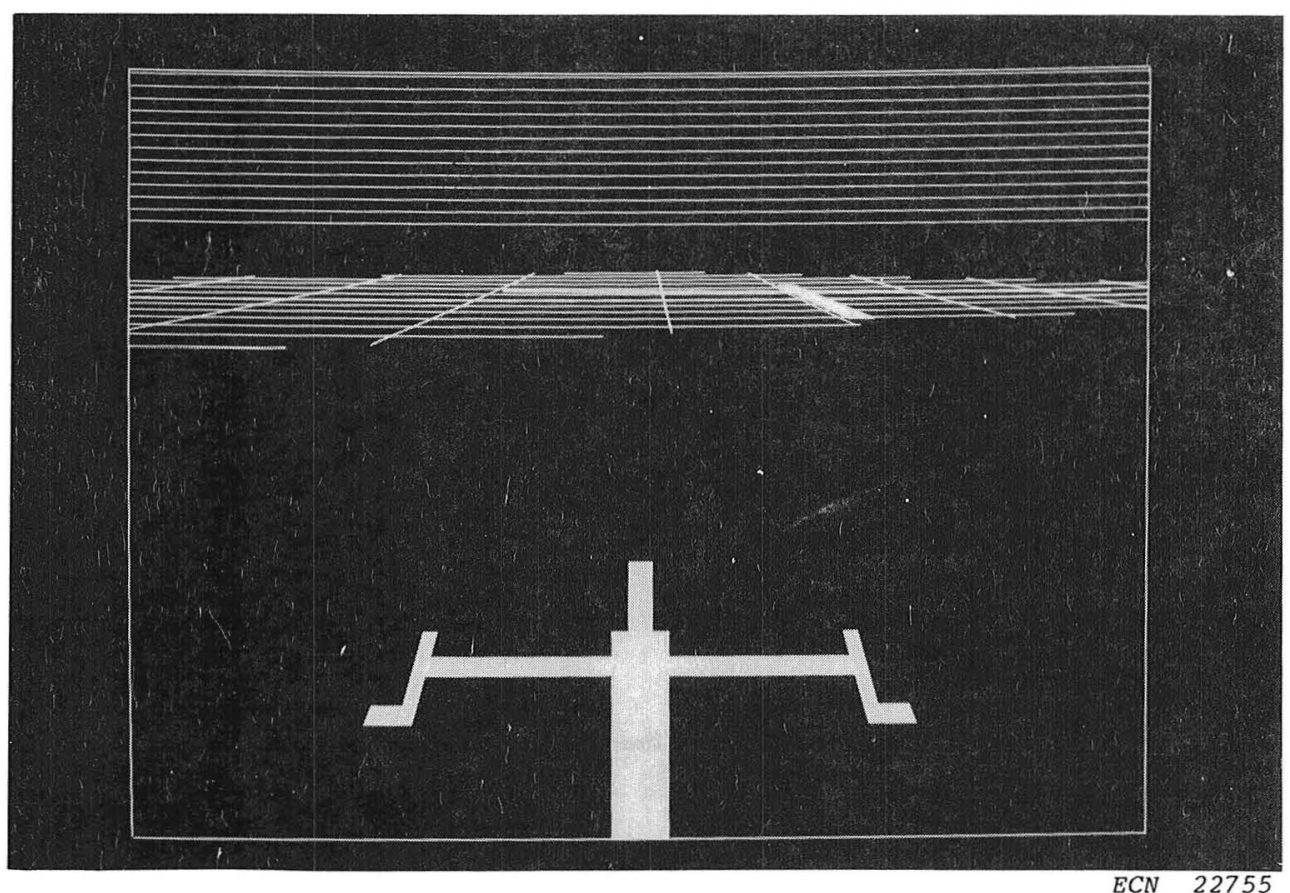

Fig. 8 Simulated landing approach initial conditions; visual display, lateral off set.

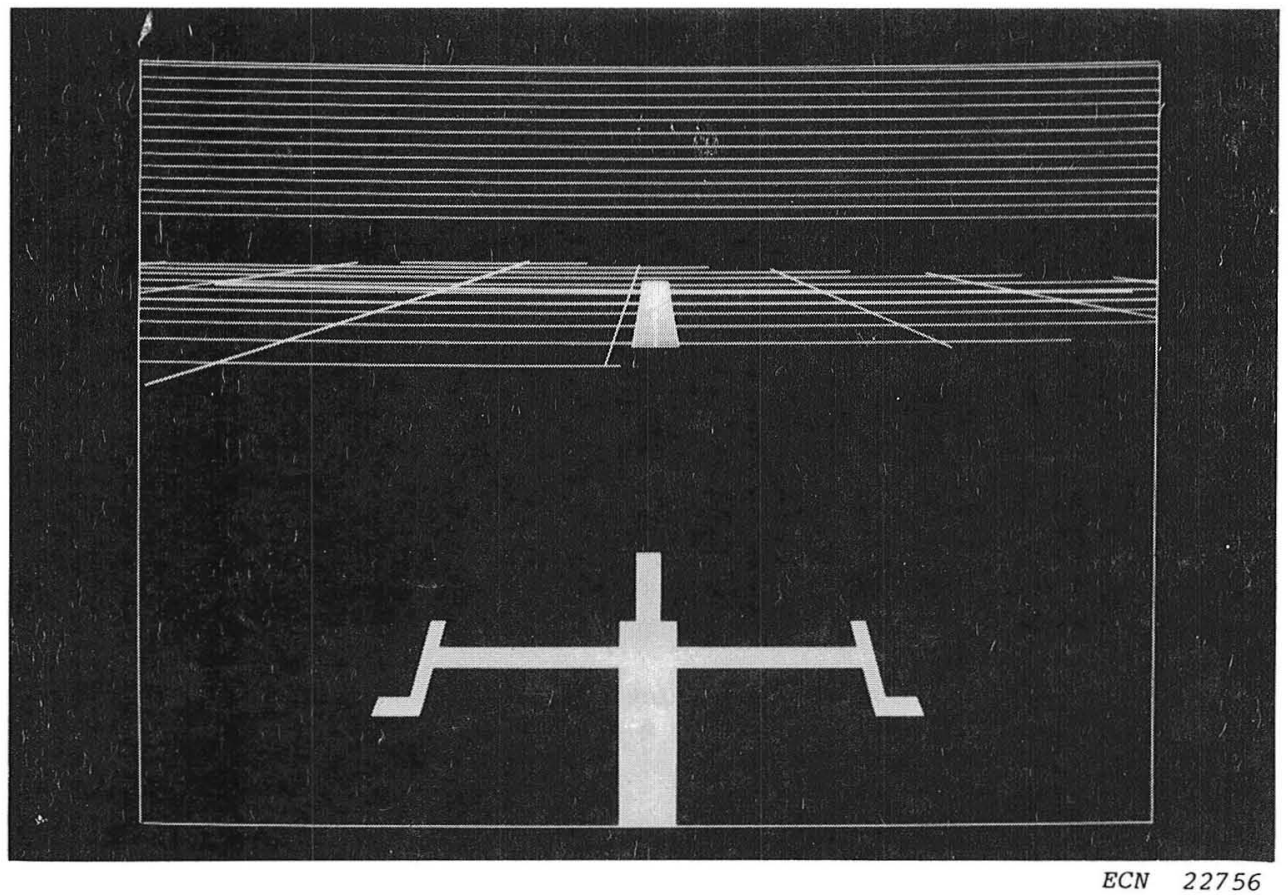

Fig. 9 Simulated landing approach conditions on glideslope. 


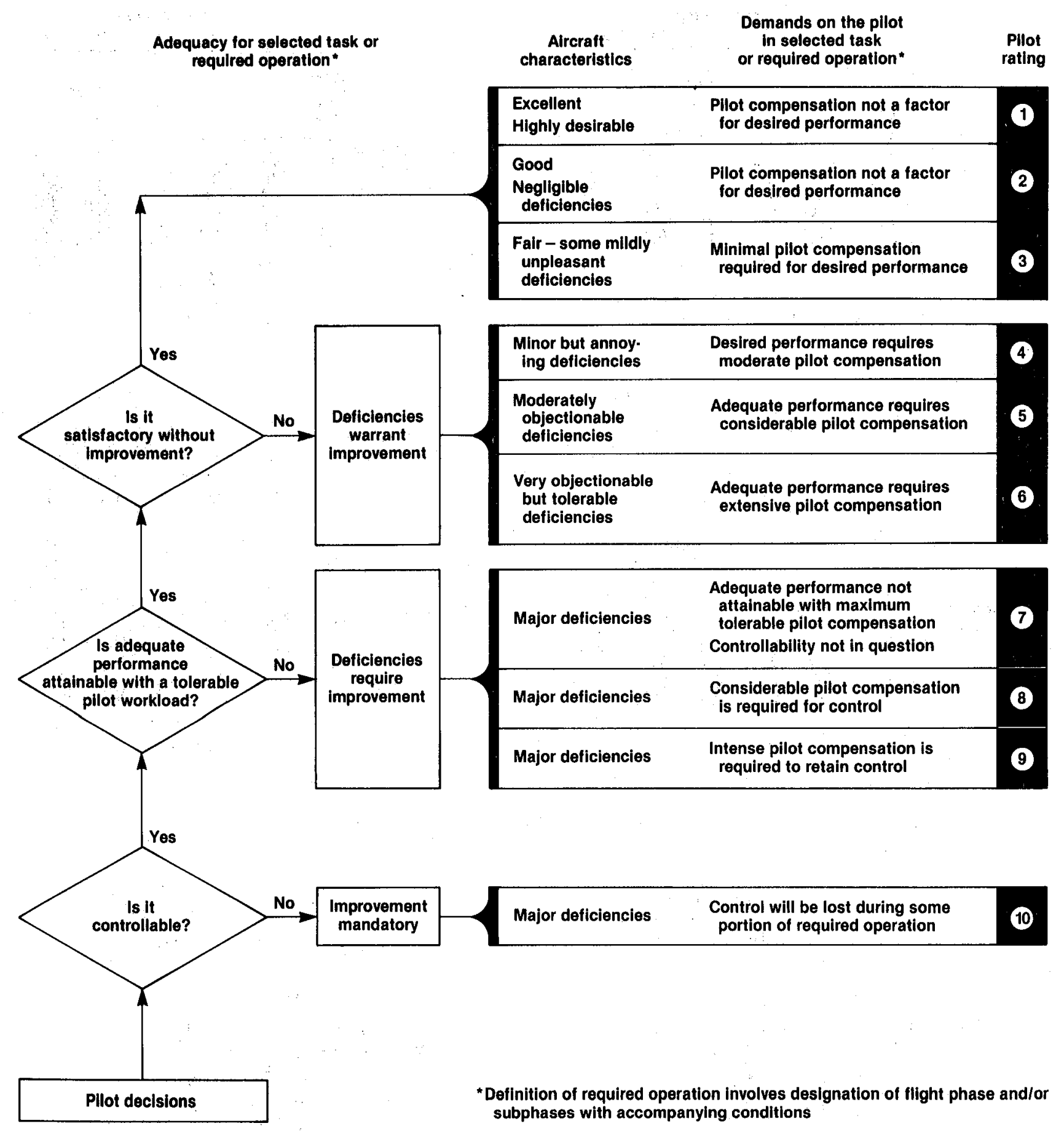

Fig. 10 Cooper-Harper pilot rating scale. 


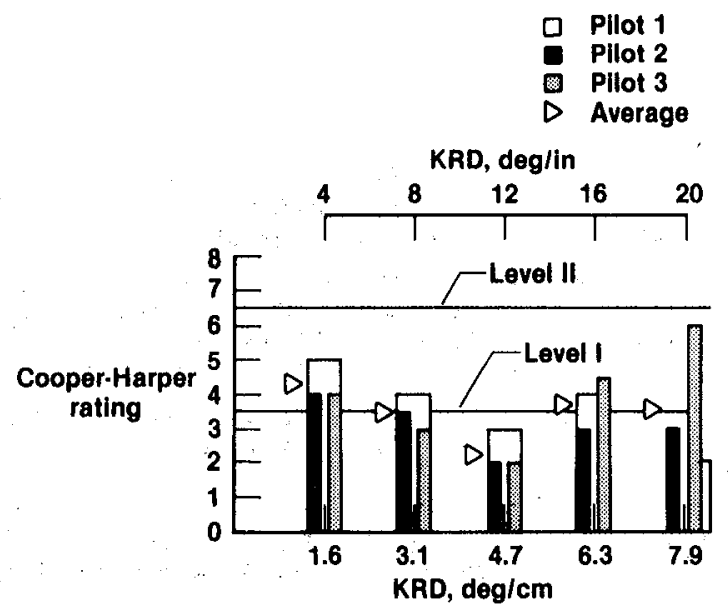

(a) ILS, calm.

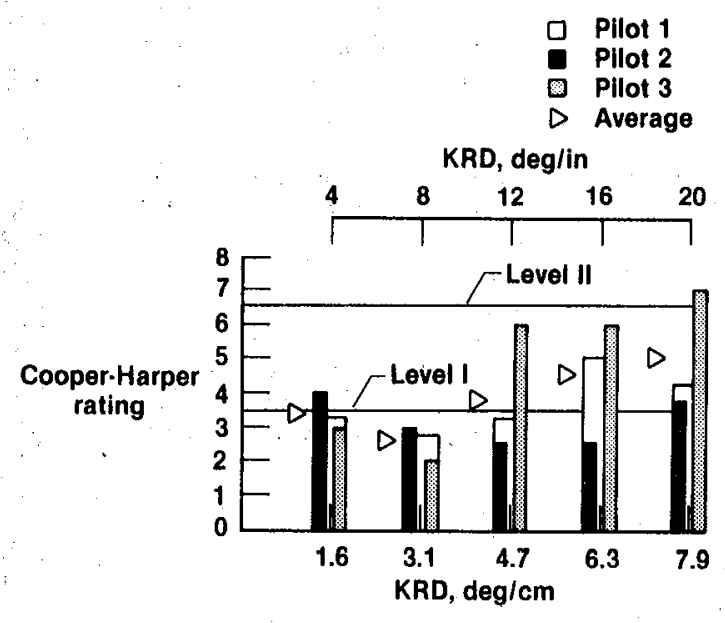

(c) Visual display, calm.

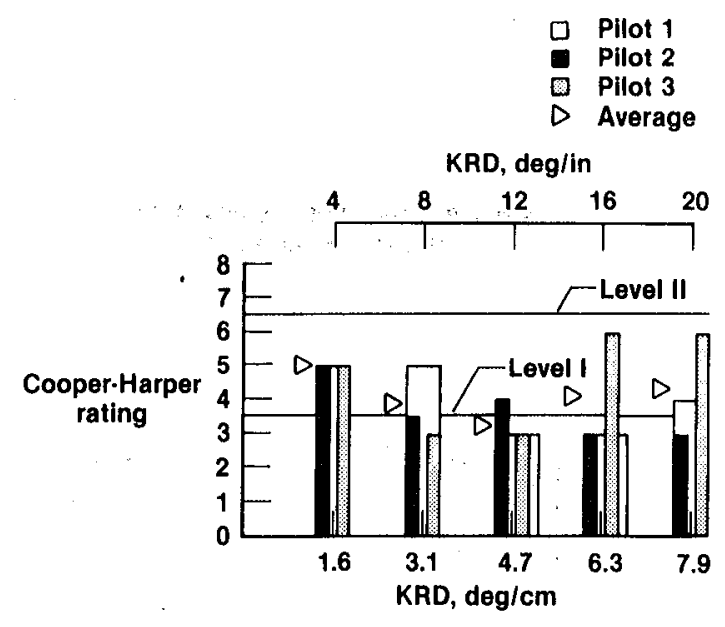

(b) ILS, gusts.

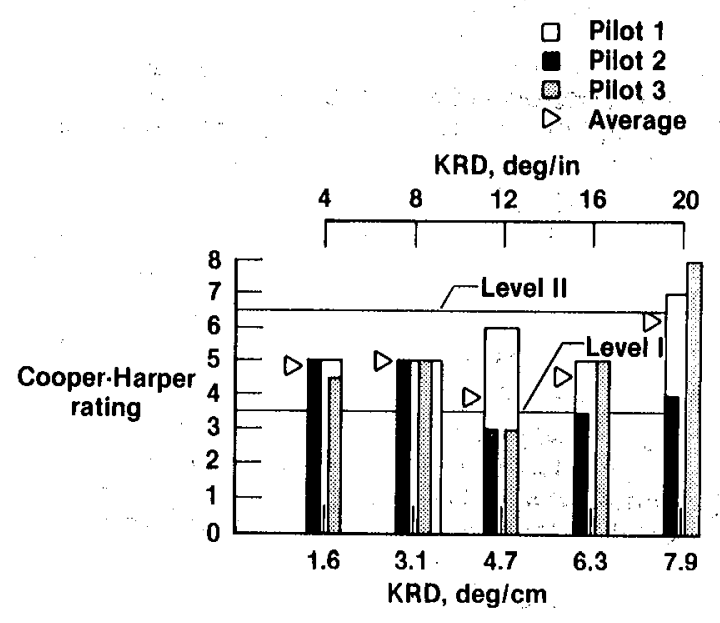

(d) Visual display, gusts.

Fig. 11 Simulation handling qualities results. ·

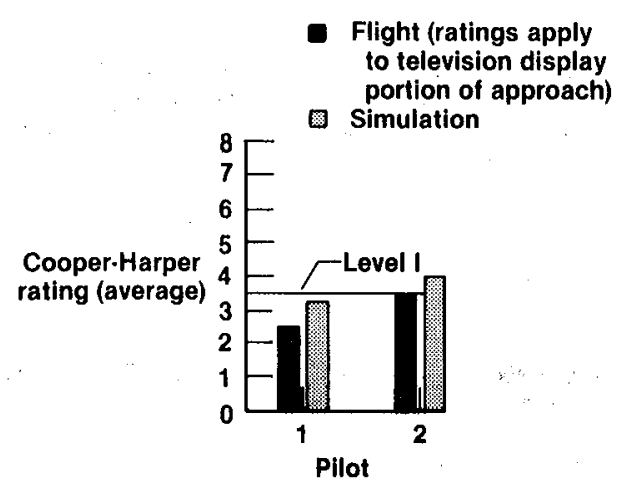

(a) Visual display.

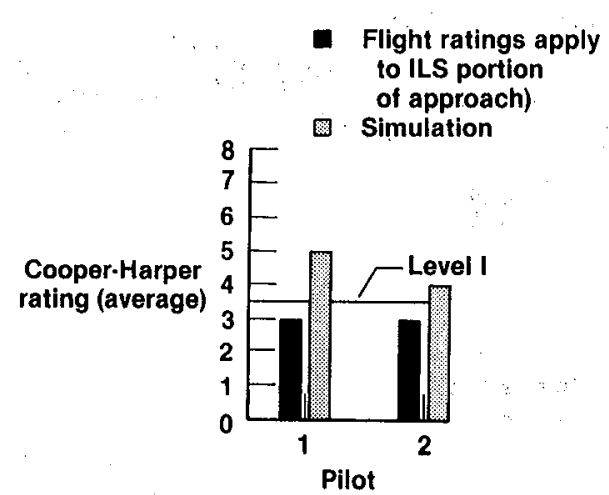

(b) ILS display.

Fig. 12 Comparison of flight and simulation results for HiMAT vehicle approach and landing. $K R D=1.6 \mathrm{deg} / \mathrm{cm}$ (4 deg/in); calm air. 


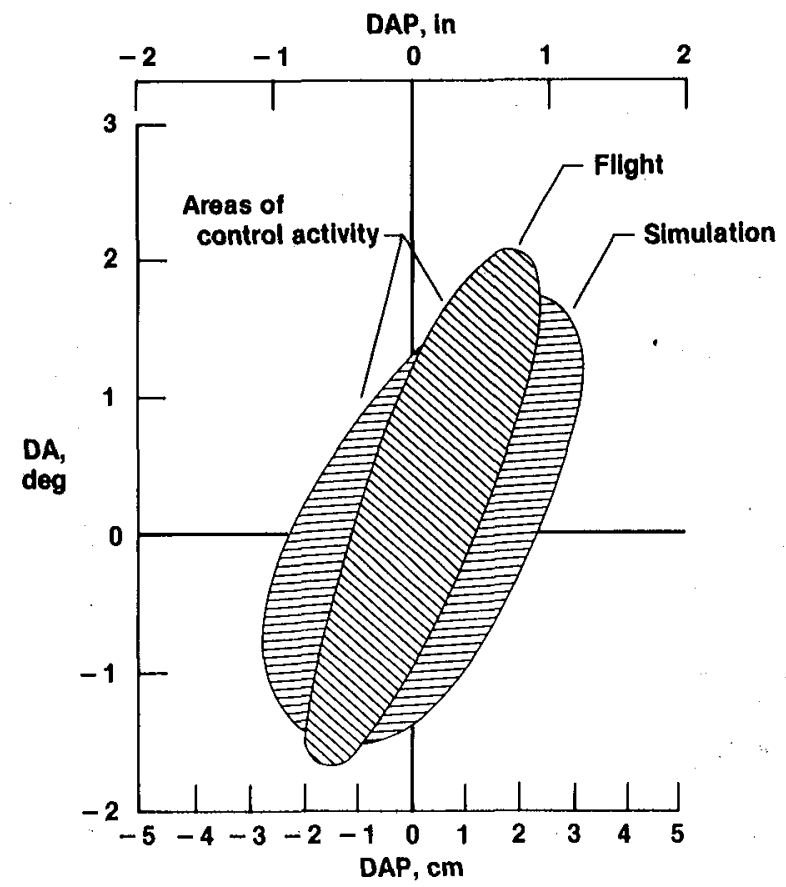

Fig. 13 Comparison of lateral control activity for HiMAT vehicle landing approach.

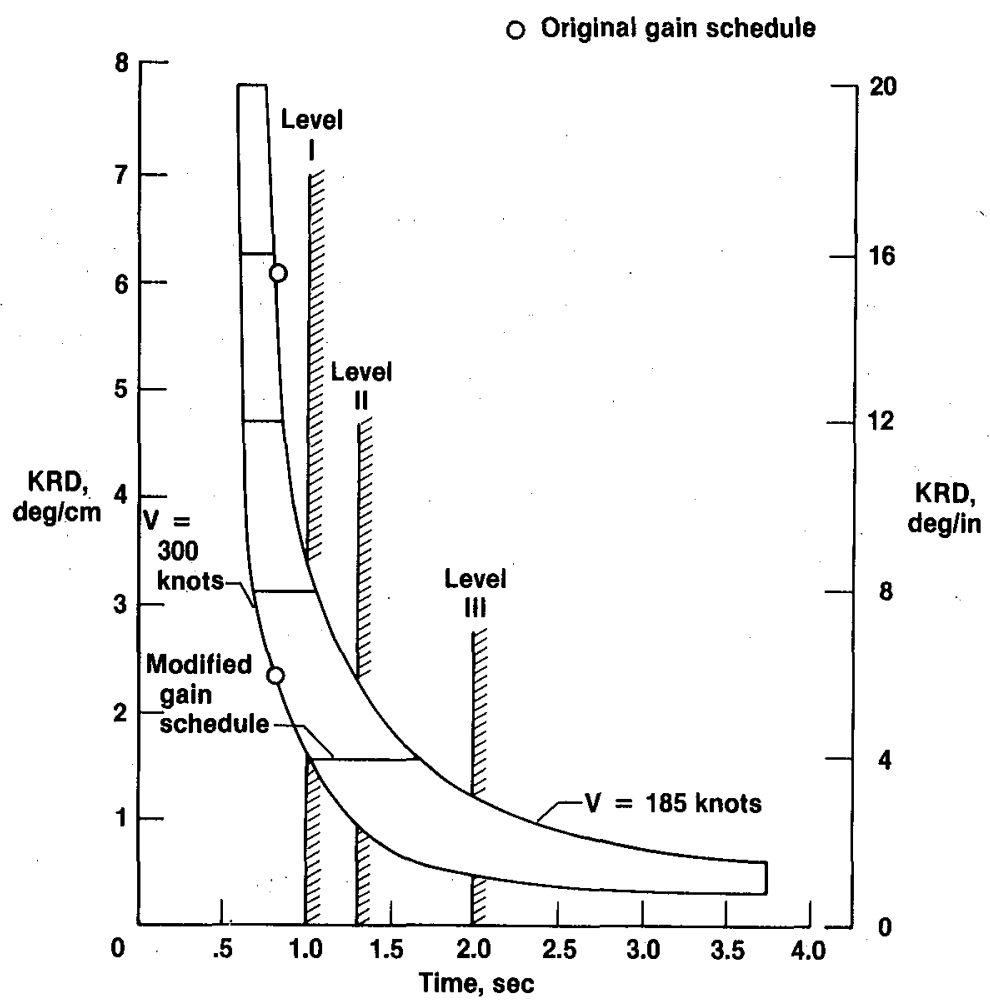

Fig. 14 HiMAT simulation landing approach time to $30^{\circ}$ bank. Altitude $=1219 \mathrm{~m}(4000 \mathrm{ft})$; maximum lateral stick $= \pm 10.8 \mathrm{~cm}$ $( \pm 4.25$ in). 


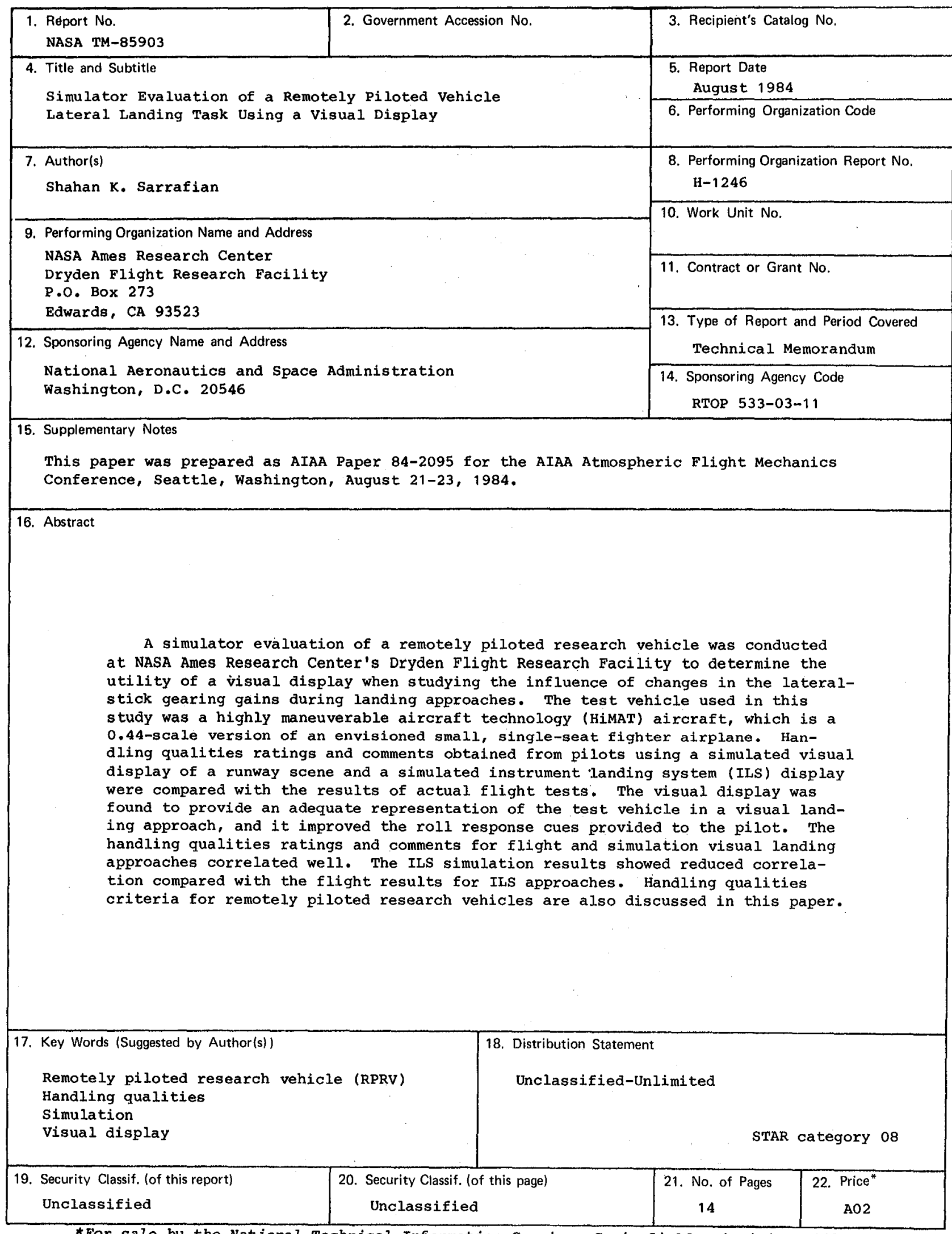

*For sale by the National Technical Information Service, Springfield, Virginia 22161. 
